\section{Estimating the Relative Abundance of Flush Shoots in Citrus with Implications on Monitoring Insects Associated with Flush}

\author{
David G. Hall ${ }^{1}$ \\ U.S. Department of Agriculture, Agricultural Research Service, U.S. \\ Horticultural Research Laboratory, Subtropical Insects Research Unit, \\ 2001 South Rock Road, Fort Pierce, FL 34945
}

\section{L.G. Albrigo}

University of Florida, Citrus Research and Education Center, 700 Experiment Station Road, Lake Alfred, FL 33850

Additional index words. Diaphorina citri, Phyllocnistis citrella, Toxoptera citricida, sampling, monitoring

\begin{abstract}
Attention to the management of insects that feed on foliar flush growth has increased in Florida citrus as a result of the establishment of invasive plant diseases associated with insects that develop exclusively on flush. Citrus can be monitored to identify peak periods of flush abundance to time insecticide applications for these insects; however, guidelines for quantifying flush abundance are lacking. We therefore investigated sampling procedures for estimating flush abundance. A sampling method was devised to enable a quantitative estimation of flush shoots, defined as any shoot with immature leaves. A sample unit was the area within a $15 \times 15 \times 15-\mathrm{cm}$ frame slipped into the outer edge of a tree with the end of a branch inside the frame. The number of flush shoots originating within the sample unit was counted. Three sample units were examined per tree in 45 randomly selected trees weekly during 2005 in each of two blocks of trees, one containing young 'Marsh' grapefruit (Citrus paradise Macf.) and one containing mature 'Temple' orange (tangors) $[C$. reticulate Blanco $\times C$. sinensis $(\mathrm{L}$.) Osbeck]. A pronounced abundance of flush was generally indicated by means of one or more flush shoots per sample in the particular trees studied. Variation in numbers of flush shoots per sample was similar within and among trees, differed significantly among sample dates, and did not differ significantly between the two blocks of trees overall sample dates. Taylor's power law coefficients indicated that, over all sample weeks, flush shoots were randomly distributed within the young grapefruit trees and only weakly aggregated within the block of mature oranges. Projections indicated that a sampling plan consisting of 40 trees (one sample per tree) would provide density estimates acceptable enough for general estimates at mean densities of one or more shoots per sample. An index of pest abundance based on mean pest density per flush shoot and mean density of flush shoots per sample is proposed.
\end{abstract}

The need to manage insects that feed on foliar flush growth has increased in Florida citrus as a result of recent establishment of invasive plant diseases promoted by insects that develop exclusively on flush growth, notably Huanglongbing (citrus greening) disease vectored by Asian citrus psyllid (Diaphorina citri Kuwayama) (Halbert and Manjunath, 2004; Hall, 2005) and citrus canker in which symptoms are exacerbated by the citrus leafminer (Phyllocnistis citrella Stainton) (Browning et al., 1995; Graham et al., 2004). A number of other insect pests at some stage of their development feed exclusively on citrus flush growth. Flush is subject to attack by adults of citrus root weevils such as Diaprepes root weevil [Diaprepes abbre-

Received for publication 28 July 2006. Accepted for publication 6 Nov. 2006.

${ }^{1}$ To whom reprint requests should be addressed; e-maildhall@ushrl.ars.usda.gov.
Citrus trees produce at least several flushes of new growth each year. Mature trees in Florida typically produce major flushes of growth during early spring and summer and sometimes minor flushes of growth during late summer and fall. These flushing periods are usually synchronized with all trees across a block producing flush at the same time. There may be little or no production of new leaves between these major and minor flushing periods. Young citrus trees also exhibit flushes of new growth each year generally at the same times as older trees, but periods of flush growth by young trees may be less synchronized than older trees. Young trees often appear to flush almost continually during favorable weather conditions. Management of insects attacking flush may therefore be needed more frequently in young trees than older trees. However, in both young and older trees, there may be times during a year that flush shoots are present but not enough to justify an insecticide treatment. Working with 10 - to 20-year-old 'Navelina' sweet oranges and 'Clemenules' Clementine mandarins, Garcia-Marí et al. (2002) reported from 1728 to 3822 new shoots per tree per year in Spain during March through November with $51 \%$ to $96 \%$ of the flush shoots generated during the spring. Cooper et al. (1963) reported data indicating that $76 \%$ to $87 \%$ of the annual new flush shoots were produced during February and March by mature 'Valencia' orange trees in Florida. Seasonal flushing patterns may differ among regions, varieties, plant age (Knapp et al., 1995), and from year to year. Total leaf area per flush shoot varies from flush to flush in Florida citrus with more flush shoots occurring in trees during the spring than summer but with larger leaves, greater numbers of leaves per shoot, and more leaf area produced during the summer (Albrigo, unpublished data).

A flush shoot may be defined as any shoot with immature leaves but can range from as small as newly breaking buds of just feather flush to fully elongated shoots with expanded, tender leaves. New flush shoots are produced from buds at the node at the base of mature citrus leaves. Up to three shoots can be produced from the buds associated with each leaf. If and when a bud begins to develop into a shoot depends on a number of factors, including environmental and tree health conditions. Developmental progression of a new flush shoot begins with enlargement of the bud and the generation of tiny, unexpanded, light green leaflets often referred to as feather flush. Approximately $5 \mathrm{~d}$ may be required from budbreak until feather leaves appear (Albrigo, 1996). These new growth flush leaves are initially light yellow-green in color and are thin and supple (Syvertsen et al., 1981). As these leaflets enlarge and expand, a flush shoot's tender stem increases in length and diameter and additional new leaflets are produced at the tip of the shoot. From 13 to $15 \mathrm{~d}$ may be required from the time feather leaves first appear until basal flush leaves are fully expanded, and 
each additional leaf may require another 1 to $1.5 \mathrm{~d}$ to complete expansion (Albrigo, 1996). After several weeks of development, a flush shoot stops producing new leaflets at the tip and all of the new light green leaves produced will complete expansion and begin to turn dark green and become more leathery (Syvertsen et al., 1981). Development of a flush shoot with 10 leaves requires $\approx 30 \mathrm{~d}$ from budbreak to full expansion of all 10 leaves (Albrigo, 1996). When a tree first enters a period of flush growth, there may be numerous buds with new leaflets present that cannot be seen from a distance. As the flush progresses and new leaves get larger, it becomes obvious even from a distance that a flush is underway as a result of a color change of the canopy (lighter green in color).

Specific guidelines were lacking on quantifying flush abundance for the purpose of pest management decisions. Although no sampling procedures have been formalized, some methods of assessing numbers of flush shoots in citrus have been reported. For example, Cooper et al. (1963) used a $0.6 \times$ $0.6-\mathrm{m}$ frame as a guide to counting shoots, taking a count in each compass quadrant of a tree at $\approx 1.8 \mathrm{~m}$ above the ground. The total number of flush shoots within a $0.25-\mathrm{m}^{2}$ ring placed in each compass quadrant of the tree canopy was used by Hermoso de Mendoza et al. (2001) and Marroquín et al. (2004) to estimate the density of shoots per $\mathrm{m}^{2}$ canopy in citrus. Catling (1969) estimated flush densities by counting all flush shoots within a square frame held against the canopy of a tree at a random height in each compass quadrant, a $0.4-\mathrm{m}^{2}$ frame in small trees and $1.5-\mathrm{m}^{2}$ frame in large trees.

The objectives of our research were to establish procedures that could be used to investigate flushing patterns of trees and to assist in gauging the relative abundance of insect pests that develop exclusively on flush. We report the results of research on sampling to estimate the relative abundance of flush shoots in citrus over a season to establish some guidelines for developing an appropriate monitoring procedure. We investigated counting the number of flush shoots within a $3.375-\mathrm{dm}^{3}$ sample area at the outer edge of tree branches as a sample unit for assessing the relative abundance of flush shoots and calculated optimum numbers of samples required to make mean flush density estimates per sample unit.

\section{Materials and Methods}

This research was conducted at two citrus groves, one in Saint Lucie County and one in Indian River County. The Saint Lucie County grove was located at a USDA-ARS research farm containing many blocks of trees of various ages and scion/rootstock combinations. The particular block chosen for the study was 0.2 ha in size $(2.7-\mathrm{m}$ tree spacing, 7.5-m row spacing) and contained 'Marsh' grapefruit (Citrus paradise Macf.) trees (2.5 years old, $\approx 1.3 \mathrm{~m}$ tall) on the rootstock 'Sun Chu Sha' mandarin (C. reticulata Blanco).
The Indian River County grove was a 1.0-ha block (4.6-m tree spacing, 9.1-m row spacing) of 'Temple' tangor [C. reticulate Blanco $\times C$. sinensis (L.) Osbeck] trees (36 years old, $\approx 3.4 \mathrm{~m}$ tall) on the rootstock 'Cleopatra mandarin' (C. reshni Hort. ex Tan.). Tangors are commonly referred to as oranges. The trees at each study location were subjected to a standard, seasonal nutritional program, although the specific programs differed. No pesticides were applied to either grove. No hedging activities were conducted in the trees during the study or during the year before the study. Sampling for citrus flush growth was conducted weekly from Jan. through Dec. 2005. Forty-five trees were randomly selected each week at each study location. The quantity of flush at each study site was assessed each week by counting the number of flush shoots originating within a cubic square frame $(15.24 \times 15.24 \times 15.24 \mathrm{~cm}$, $3.375 \mathrm{dm}^{3}$ ) placed into the outer canopy of each tree (the end of a branch inside the frame) at three locations 1 to $2 \mathrm{~m}$ aboveground. Our frame was made of PVC pipe and fittings (size $1.27 \mathrm{~cm}, 2.13 \mathrm{~cm}$ o.d.). A flush shoot was defined as any shoot with immature leaves (up to fully expanded but not hardened off) and therefore ranged from newly breaking buds of just feather flush to elongated shoots with expanded, tender leaves.

Flush at the two study sites was evaluated graphically by plotting mean numbers of flush shoots per sample per week over the 52 -week study. Mean and variance for the number of flush shoots per sample were computed for each sample date at each location, and homogeneity of the variances was investigated using simple linear regression of variances on means. The spatial distribution of flush was assessed using Taylor's power law $\left(\mathrm{s}^{2}=a \overline{\mathrm{x}}^{b}\right.$; Southwood, 1978; Taylor, 1961) and a nested analysis of variance (PROC NESTED, SAS Institute, 1999) (Snedecor and Cochran, 1967). Taylor's law has been applied widely in arthropod dispersion studies, but it has also been useful for characterizing variance-mean relationships for other sampling interests such as spatial variability of weeds (Clark et al., 1996) and seeds in soil (Ambrosio et al., 2004). The $a$ and $b$ coefficients of Taylor's power law were derived from a simple linear regression of sample means and variances (logarithm transformed), with $a$ being the intercept and $b$ the slope from the regression. A random dispersion is indicated by $b=1.0$; a uniform dispersion is indicated when $b<1.0$; and an aggregated dispersion is indicated when $b>1.0$ (Harcourt, 1965; Southwood, 1978; Taylor, 1961). The intercept $a$ is largely a sampling factor related to sample size (Southwood 1978). A nested analysis of variance (PROC NESTED, SAS Institute, 1999) (Snedecor and Cochran, 1967) over all sample dates at both locations was conducted to derive variance components associated with each hierarchical level of the sampling plan (individual samples nested in trees nested in sample date nested in location) and to determine the percentage contribution of each hierarchical level to total variance in shoot counts. Mean $(\overline{\mathrm{x}})$ and standard error of the mean (SEM) for the number of flush shoots per sample based on individual nested analysis of variance for each sample date at each location were used to calculate relative sampling variation $(\mathrm{RV})(\mathrm{RV}=\mathrm{SEM} / \overline{\mathrm{x}} \times 100)$. $\mathrm{RV}$ is a convenient gauge of the precision of a mean estimate. RV values of $25 \%$ or less may be acceptable for general estimates, whereas $\mathrm{RVs}$ of $10 \%$ or less may be mandatory for some research purposes (see Southwood, 1978). For each sample date at each location, the number of samples required to achieve an $\mathrm{RV}$ of $25 \%$ were projected based on variance components from each nested analysis of variance (Snedecor and Cochran, 1967). These optimum sample sizes were then plotted against mean flush densities per sample. Analyses on sampling statistics were restricted to data from weeks during which flush was observed in both blocks to provide a balanced data set for the hierarchical analyses.

\section{Results and Discussion}

An overview of the abundance of flush in the young 'Marsh' grapefruit and mature 'Temple' orange trees during 2005 is presented in Figure 1. Based on empiric observations, the 2005 flushing profiles for these trees appeared at least somewhat typical with respect to flushes during March and summer but less so with respect to flushes during January and late November. Relative to the range of flush densities we observed, means of one or more flush shoots per sample appeared large enough to constitute an abundance of flush. However, our intent was to establish a method of estimating the relative abundance of flush, not to characterize flushing cycles or to define what constitutes a major or minor flush. Because no published data were available on flush densities in Florida citrus, it remains to be determined if the mean densities of flush we observed would be indicative of an abundance of flush in other years or situations. Just as seasonal flushing patterns may differ among regions, varieties, tree age (Knapp et al., 1995), tree health and environmental conditions, so may the quantity of flush produced. More research is needed to evaluate ranges in mean number of flush shoots per sample that can occur in Florida citrus and to identify densities of flush shoots per sample that constitute minor and major flushes during years that may be more normal than 2005 .

The mature trees produced a major flush during late Jan. 2005 (approaching a mean of 10 shoots per sample), apparently in response to extensive defoliation incited by Hurricanes Francis (4 Sept. 2004) and Jeanne (25 Sept. 2004) and in conjunction with favorable weather conditions. There was a corresponding but minor flush at this time in the young grapefruit trees (peak of just above one shoot per sample). A major flush occurred during March, reaching just over an average of eight 
shoots per sample in both the grapefruit and orange trees. Flush shoots were present in each block of trees continually during May through August and in the young grapefruit through mid-September. The late November flush in the young grapefruit trees was attributed in part to leaf damage and leaf loss associated with Hurricane Wilma (24 Oct. 2005). There were 2 and 11 weeks during 2005 during which no flush was observed in the young and mature trees, respectively. This indicated that if insect pests attacking flush are continually present, insect control would have been needed nearly all year long in the young trees and almost four-fifths of the year in the mature trees during 2005. There were 40 weeks during which flush was observed in both blocks of trees.

Regression analyses revealed that sample variance increased as the mean number of flush shoots per sample increased (for the young grapefruit trees $\mathrm{F}=29.3, \mathrm{Pr}>\mathrm{F}=$ $<0.0001, \mathrm{r}^{2}=0.44$, df $=39$; for the mature 'Temples' $\mathrm{F}=115.8, \operatorname{Pr}>\mathrm{F}=<0.0001, \mathrm{r}^{2}=$ $0.75, \mathrm{df}=79$; overall data $\mathrm{F}=132.8, \operatorname{Pr}>\mathrm{F}=$ $<0.0001, \mathrm{r}^{2}=0.63$, df $\left.=79\right)$. The heterogeneity of variances among samples taken in the young grapefruit trees was eliminated by transforming the data to $\log (\mathrm{x}+1)(\mathrm{F}=3.7$, $\left.\operatorname{Pr}>\mathrm{F}=<0.06, \mathrm{r}^{2}=0.09, \mathrm{df}=39\right)$. Transforming the data to $\log _{s}$ reduced the heterogeneity of variances among samples taken in the mature 'Temples' $(\mathrm{F}=28.2, \mathrm{Pr}>\mathrm{F}=$ $<0.0001, \mathrm{r}^{2}=0.43, \mathrm{df}=39$ ). For data taken in the mature 'Temples', no heterogeneity of variances was found among means greater than 0.2 flush shoots per sample when the data were $\log$-transformed $(\mathrm{F}=3.1, \mathrm{Pr}>\mathrm{F}=$ $<0.09, \mathrm{r}^{2}=0.11, \mathrm{df}=27$ ).

Taylor's power law coefficients indicated that, overall sample weeks, flush shoots were randomly distributed within the block of young grapefruit trees and weakly aggregated within the block of mature oranges (Fig. 2). Analyses of the combined data indicated flush was randomly distributed. The fitted Taylor parameters were: for the young grapefruit samples, $a=0.92$ (standard error $0.09, a$ significantly different from 0 , not significantly different from 1$), b=0.90$ (standard error $0.07, b$ significantly different from $0, b$ not significantly different from 1 ) $\left(\mathrm{F}=180.6, \operatorname{Pr}>\mathrm{F}=<0.0001, \mathrm{df}=39, \mathrm{r}^{2}=0.83\right)$; for mature 'Temple' samples, $a=0.86$ (standard error $0.07, a$ significantly different from both 0 and 1), $b=1.11$ (standard error $0.03, b$ significantly different from $0, b$ significantly different from 1) $(\mathrm{F}=1020.7, \operatorname{Pr}>\mathrm{F}=$ $<0.0001$, df $=39, \mathrm{r}^{2}=0.96$ ); and over both the young and mature trees, $a=0.88$ (standard error $0.06, a$ significantly different from 0 , not significantly different from 1$), b=1.05$ (standard error $0.04, b$ significantly different from $0, b$ not significantly different from 1 ) $\left(\mathrm{F}=887.8, \operatorname{Pr}>\mathrm{F}=<0.0001, \mathrm{df}=79, \mathrm{r}^{2}=0.92\right)$.

Nested analyses of variance indicated that statistical variation in numbers of flush shoots per sample was similar within and among trees, differed significantly among sample dates, and did not differ significantly between the two blocks of trees (Table 1).


Fig. 1. Mean number of flush shoots per sample in young 'Marsh' grapefruit and mature 'Temple' orange trees during 2005.

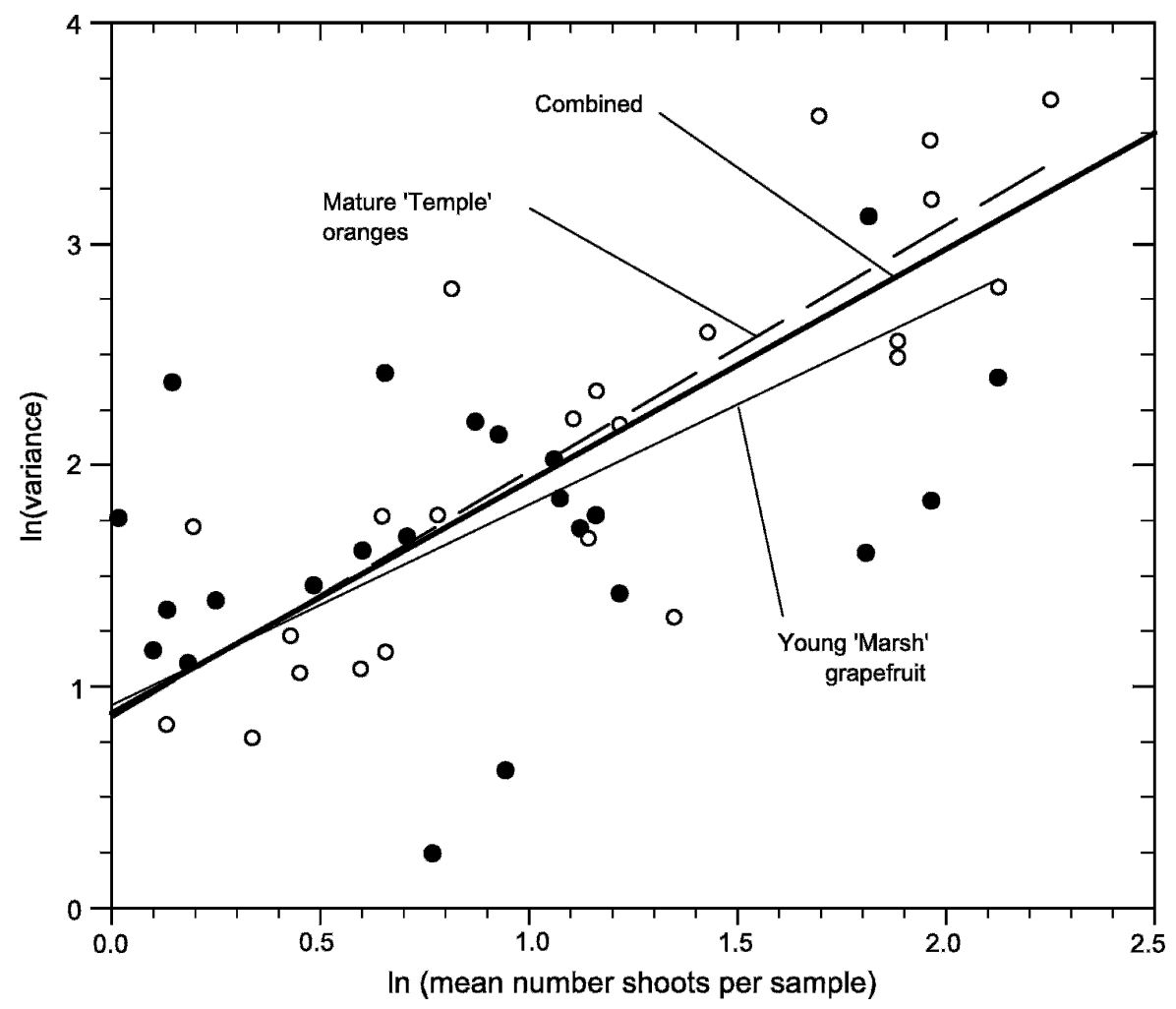

Fig. 2. Relationship of logarithm (variance) to logarithm (mean) number of flush shoots per sample for flush count data taken in young grapefruit (solid points) and mature orange trees (open points). Consult text for sampling details.

Variation in flush within and among trees accounted for $26.0 \%$ and $25.5 \%$, respectively, of the total variance associated with number of flush shoots per sample based on raw data counts and $26.2 \%$ and $22.7 \%$, respectively, based on log-transformed data. Relative sampling variation associated with raw data counts (overall RV mean $=25.2$, SEM 2.3) was large (e.g., $>25 \%$ ) when the mean density of flush shoot per sample was small (e.g., $<0.3$ shoots per sample). RV values decreased (improved) as the mean density increased (Fig. 3). RV values associated with the raw data were generally less than $25 \%$ at mean densities of one or more shoots per sample and less than $15 \%$ at mean densities above three shoots per sample. Transforming the data to $\log (\mathrm{x}+1)$ reduced $\mathrm{RV}$ values 
Table 1. Results of nested analysis of variance on mean number of flush shoots per sample. ${ }^{\mathrm{z}}$

\begin{tabular}{|c|c|c|c|c|c|c|c|c|}
\hline Variance source & df & Sum of squares & F Value & $\operatorname{Pr}>F$ & Error term & Mean square & Variance component & Percent of total \\
\hline \multicolumn{9}{|c|}{ Analyses on raw data } \\
\hline Block & 1 & 584.7 & 0.79 & 0.3776 & Date & 584.7 & -0.0292 & 0.0 \\
\hline Date & 78 & 57,923 & 64.09 & $<0.0001$ & Tree & 742.6 & 5.4149 & 48.4 \\
\hline Tree & 3520 & 40,787 & 4.06 & $<0.0001$ & Error & 11.6 & 2.9108 & 26.0 \\
\hline Error & 7200 & 20,555 & & & & 2.9 & 2.8549 & 25.5 \\
\hline \multicolumn{9}{|c|}{ Analyses on $\log (x+1)$ data } \\
\hline Block & 1 & 14.5 & 0.27 & 0.6054 & Date & 14.5 & -0.0073 & 0.0 \\
\hline Date & 78 & 4192.1 & 69.19 & $<0.0001$ & Tree & 53.7 & 0.3924 & 51.1 \\
\hline Tree & 3520 & 2734.4 & 4.45 & $<0.0001$ & Error & 0.8 & 0.2008 & 26.2 \\
\hline Error & 7200 & 1256.9 & & & & 0.2 & 0.1746 & 22.7 \\
\hline
\end{tabular}

${ }^{z}$ The data set consisted of counts of flush shoots per sample: three samples per tree, 45 trees per block on 40 dates in each of two blocks of trees (one 0.2 -ha block of young grapefruit trees, one 1.0-ha block of mature orange trees). ${ }^{y}$ Consult text for sampling details.

${ }^{\mathrm{y}}$ The overall mean number of shoots per sample was 2.07 (SEM 0.23).

(overall RV mean = 23.0, SEM 2.3) (Fig. 3). $\mathrm{RV}$ values indicated that a sampling plan consisting of fewer than our 135 samples (three samples per tree, 45 trees per block) would provide enough precision for general estimates at mean densities of one or more shoots per sample. Projections from variance component analyses on log-transformed data indicated that RV values of $25 \%$ or less at mean densities of one or more flush shoots per sample would be achieved by sampling 25 trees taking two samples per tree (total $\mathrm{n}=50$ ) or by sampling 40 trees taking one sample per tree (total $n=40$ ) (Fig. 4).

The results of this study provide sampling guidelines for estimating the relative abundance of flush shoots in a block of citrus trees of up to $\approx 1$ ha in size. For larger blocks, if the trees are of the same variety, subjected to the same management program, and uniform in size, a similar number of samples could be taken but spread out further across the block providing soil, moisture, and other conditions are similar throughout. Additional research is needed to clarify sample size and allocation for estimating the relative abundance of flush in blocks larger than 1 ha in size that may be less uniform. For any given level of sampling precision, the optimum number of samples to examine will decrease as the relative amount of flush increases. If the purpose of sampling flush is to identify the beginning of a blockwide flush, our data indicated that regular sampling could be initiated using a sampling plan fit for a threshold of one shoot per sample (i.e., one sample per tree from 40 trees). The precision level provided by $\mathrm{RV}=25 \%$ would allow the statistical distinction based on SEM of a mean of 1.0 from a mean of 0.75 shoots per sample or of a mean of 1.0 from a mean of 1.25 shoots per sample. However, because no published data were available on relative abundances of flush in Florida citrus, it remains to be determined if a threshold of one shoot per sample would be appropriate in all situations for identifying when citrus is entering a peak period of flush abundance. The threshold might be different for some groves depending on factors such as variety, soil type, tree management programs, and environmental conditions. The study results may be applied to estimating the density of



Fig. 3. Relative variation (SEM/mean*100, sEM derived from variance components) in flush shoot counts taken in young grapefruit and mature orange trees. Solid data points - raw data. Open data points - log-transformed data. Equations for general predictions of relative variation were for means of raw data (dashed line) $\mathrm{Y}=1 /(0.0159+0.0356 \mathrm{X}) ;\left(\mathrm{F}=193.0, \operatorname{Pr}>\mathrm{F}=0.0001, \mathrm{r}^{2}=0.71, \mathrm{df}=79\right)$ and for means of $\log$ data (solid line) $\mathrm{Y}=1 /(0.0154+0.0497 \mathrm{X}) ;\left(\mathrm{F}=206.3, \operatorname{Pr}>\mathrm{F}=<0.0001, \mathrm{r}^{2}=0.73\right.$, $\mathrm{df}=79)$. The dotted line references $25 \%$ relative variation. Three samples on each of 45 trees for a total of 135 samples per data point. Consult text for sampling details.

flush shoots with feather flush if only these are counted. Feather flush would be present for a shorter period of time during a period of flush growth and probably only sufficiently synchronized during a major flush. Estimating the density of flush shoots with feather flush would be of interest with respect to monitoring flush for eggs of Asian citrus psyllid or citrus leafminer, insects that lay their eggs primarily on feather flush (Browning et al., 1995; Halbert and Manjunath, 2004). In addition to monitoring flush abundance to make pest management decisions, the sampling procedures presented here could be used to estimate the relative abundance of citrus flush to compare different citrus varieties, nutritional treatments, treatments to synchronize or reduce flushes for improved pest control, and other factors with respect to flush production.

A spray program for an insect that develops on flush may be less effective if it is based on calendar dates of expected flush growth than if it is based on the actual presence of flush. With respect to monitoring flush abundance for the purpose of making pest management decisions, if flush is monitored to identify when enough is present to warrant a chemical spray for an insect pest regardless of the infestation level of the pest, then a grower need only to monitor for peak periods of flush abundance. A particular shoot density threshold per sample must be decided on in advance as the indicator of a peak period of flush production. In our study, this appeared to be one shoot per sample (additional research is warranted to clarify the intensity of flushes in Florida citrus). Weekly sampling can be initiated and, when the mean density reaches or exceeds the threshold, a foliar insecticide applied. If the relative abundance of a flush pest is also of interest, then a grower will need to monitor both flush abundance and pest density per flush shoot. The management decision will be a function of both. In this respect, an index of the relative abundance of a flush pest can be calculated as the mean pest density per shoot multiplied by the mean number of shoots per sample. For example, an index value of 20 would be indicated by means of 10 insects per shoot and two shoots per sample, whereas an index value of two would be indicated by means of 10 insects per shoot and 0.2 shoots per sample. The index of 




Fig. 4. Number of trees to sample taking one versus two samples per tree to achieve $25 \%$ relative variation (SEM/mean $\times 100$, SEM derived from variance components, log-transformed data) in flush shoot counts taken in young grapefruit (solid points) and mature orange trees (open points). Y-axis truncated at 55. An equation for an approximate prediction for two samples per tree was $\mathrm{Y}=(-1680.465+\mathrm{X})$ / $(-1.0623-71.5844 \mathrm{X}) ;\left(\mathrm{F}=152.33, \mathrm{Pr}>\mathrm{F}=<0.0001, \mathrm{r}^{2}=0.80, \mathrm{df}=79\right)$. An equation for an approximate prediction for one sample per tree was $\mathrm{Y}=(-39.3626+\mathrm{X}) /(-0.0113-0.9468 \mathrm{X})$; $\left(\mathrm{F}=237.99, \operatorname{Pr}>\mathrm{F}=<0.0001, \mathrm{r}^{2}=0.86, \mathrm{df}=79\right)$. Consult text for sampling details.

pest abundance puts mean pest density per shoot in perspective to flush abundance.

\section{Literature Cited}

Albrigo, L.G. 1996. Seasonal leaf area development in citrus-Relation to leaf miner injury, p. 70. In: M. Hoy (ed.). Managing the citrus leafminer. Proc. from an Intl. Conf., 23-25 Apr. 1996, Orlando, Fla. University of Florida, Gainesville.

Ambrosio, L., L. Iglesias, C. Marín, and J.P. Del Monte. 2004. Evaluation of sampling methods and assessment of the sample size to estimate the weed seedbank in soil, taking into account spatial variability. Weed Res. 44:224-236.
Browning, H.W., R.J. McGovern, L.K. Jackson, D.V. Calvert, and W.F. Wardowski. 1995. Florida Citrus Diagnostic Guide. Fla. Sci. Source, Inc., Lake Alfred, Fla.

Catling, J.D. 1969. The bionomics of the South African citrus psylla, Trioza erytreae (Del Guercio) (Homoptera: Psyllidae): 1. The influence of the flushing rhythm of citrus and factors which regulate flushing. J. Entomol. Soc. Southern Africa (Lond.) 32:191-208.

Clark, S.J., J.N. Perry, and E.J.P. Marshall EJP 1996. Estimating Taylor's power law for weed species and the effect of spatial scale. Weed Research 36:405-417.

Cooper, W.C., A. Peynado, J.R. Furr, R.H. Hilgeman, G.A. Cahoon, and S.B. Boswell. 1963. Tree growth and fruit quality of Valencia oranges in relation to climate. Proc. Am. Soc. Hort. Sci. 82:180-192.

Futch, S. and C.W. McCoy. 1994. Citrus root weevils. IFAS, Univ. Fla. SP 157.

Garcia-Marí, F., C. Granda, S. Zaraagoza, and M. Agustí. 2002. Impact of Phyllocnistis citrella (Lepidoptera: Gracillariidae) on leaf area development and yield of mature citrus trees in the Mediterranean area. J. Econ. Entomol. 95:966-974.

Graham, J.H., T.R. Gottwald, J. Cubero, and D.S. Achor. 2004. Xanthomonas axonopodis pv. citri: Factors affecting successful eradication of citrus canker. Mol. Plant Pathol. 5:1-15.

Halbert, S.E. and K.L. Manjunath. 2004. Asian citrus psyllids (Sternorrhyncha: Psyllidae) and greening disease of citrus: A literature review and assessment of risk in Florida. Fla. Entomol. 87:330-353.

Hall, D.G. 2005. Overview of the Asian citrus psyllid. Proc. of the 2nd International Citrus Canker and Huanglongbing Research Workshop. Florida Citrus Mutual, Orlando, Fla., 7-11 Nov., Paper H-12, p. 60.

Harcourt, D.G. 1965. Spatial pattern of the cabbage looper, Trichoplusia ni, on crucifers. Ann. Entomol. Soc. Am. 58:89-94.

Hermoso de Mendoza, A., B. Belliure, E.A. Carbonell, and V. Real. 2001. Economic thresholds for Aphis gossypii (Hemiptera: Aphididae) on Citrus clementina. J. Econ. Entomol. 94:439-444.

Knapp, J.L., L.G. Albrigo, H.W. Browning, R.C. Bullock, J.B. Heppner, D.G. Hall, M.A. Hoy, R. Nguyen, J.E. Peña, and P.A. Stansly. 1995. Citrus leafminer, Phyllocnistis citrella Stainton: Current status in Florida-1995. Florida Cooperative Extension Service, Institute of Food and Agricultural Sciences, University of Florida, Gainesville, Fla.

Marroquín, C., A. Olmos, M.T. Gorris, E. Bertolini, M. Carmen Martínez, E.A. Carbonell, A. Hermoso de Mendoza, and M. Cambra. 2004. Estimation of the number of aphids carrying Citrus tristeza virus that visit adult citrus trees. Virus Res. 100:101-108

Michaud, J.P. 1999. Sources of mortality in colonies of brown citrus aphid, Toxoptera citricida. BioControl 44:347-367.

SAS Institute. 1999. SAS Procedures Guide, version 8. SAS Institute, Cary, N.C.

Snedecor, G.W. and W.G. Cochran. 1967. Statistical methods, 6th ed. Iowa State University Press, Ames, Iowa.

Southwood, T.R.E. 1978. Ecological methods, 2nd ed. Wiley/Halsted, N.Y.

Syvertsen, J.P., M.L. Smith, Jr., and J.C. Allen. 1981. Growth rate and water relations of citrus leaf flushes. Ann. Bot. (Lond.) 47:97-105.

Taylor, L.R. 1961. Aggregation, variance and the mean. Nature 189:732-735. 